REVISTA X, Curitiba, volume 14, n.5,p. 203-221, 2019

\title{
O QUE PODE UMA MONITORIA SIGNIFICAR NA FORMAÇÃO INICIAL DE PROFESSORES?
}

What Can a Tutoring Program Signify in Pre-Service Teacher Education?

Ricardo PEIXOTO (UFPR) ${ }^{1}$

\begin{abstract}
RESUMO: A carreira docente no contexto brasileiro tem passado por um esvaziamento - tanto em relação à evasão quanto um esvaziamento de sentido dos cursos de licenciatura. Esse é um dos motivos pelo qual necessário pensar sobre a formação inicial de professores. Partindo das discussões em Linguística Aplicada e entrelaçando-as às reflexões resultantes das atividades de um programa de monitoria em contexto de formação inicial de professores de inglês, foi possível apreender que o conteúdo linguístico não está desvinculado da vida em sociedade, contexto sociocultural e histórico, sendo necessário ter esses elementos em perspectiva para estabelecer uma relação mais horizontalizada entre os sujeitos no processo de ensino-aprendizagem. Assim, refletindo a respeito da autoimagem e síndrome do impostor (BERNAT, 2008) dentro do programa de monitoria, concepções de língua(gem) e trocas de experiências de maneiras não hierárquicas no processo de ensino-aprendizagem, este artigo objetiva construir uma narrativa em favor das práticas extracurriculares em docência, defendendo que elas poderiam ser amplamente difundidas nos cursos de licenciatura, pois a monitoria no ensino superior tem sido incentivadora, especialmente, à formação de professores e poderá assim contribuir para a redução do esvaziamento dos cursos de licenciatura e reconstrução da identidade e dos sentidos do ser professor.
\end{abstract}

PALAVRAS-CHAVE: Formação de Professores; Monitoria; Síndrome do Impostor; Língua(gem); Ensino-aprendizagem.

\begin{abstract}
Teaching career in Brazil has undergone through a deflation regarding teaching undergraduate programs, which is one of the reasons why it is necessary to think about pre-service and in-service teachers' education. Based on Applied Linguistics discussions about this matter and intertwining them with the reflections that resulted from a tutoring program inserted in an English preservice teaching education program, it was possible to apprehend that the linguistic content is not untied from life in society, sociocultural and historical context. Therefore, it is necessary to consider these elements in order to establish a horizontal relationship between subjects in teaching-learning process. Thus, by reflecting upon self-image and impostor's syndrome (BERNAT, 2008) inside the tutoring program, language conceptions and non-hierarchical ways of experience exchange in teaching-learning process, this article aims to construct a narrative in favor of teaching extracurricular practices, arguing that they should be broadly disseminated in teaching undergraduate programs. Since tutoring programs in higher education have been characterized as inspiring especially
\end{abstract}

\footnotetext{
${ }^{1}$ Graduando em Letras Português-Inglês na Universidade Federal do Paraná. rpeixoto431@ gmail.com
} 
regarding teachers' education and it can contribute to the reduction of teaching undergraduate programs deflation as well as the reconstruction of the meanings and identity of being a teacher.

KEYWORDS: Teacher Education; Tutoring; Impostor's Syndrome; Language; Teaching-learning.

\section{INTRODUÇÃO}

Muito se tem pesquisado a respeito de formação inicial e continuada de professores na Linguística Aplicada na atualidade em diversas perspectivas (CAVALCANTI, 2013; JORDÃO; FOGAÇA, 2012; JUCÁ, 2016; MEDRADO, 2016; MILLER, 2013; SILVA et al., 2017; WELP, 2016). O contexto brasileiro, no que se refere à carreira docente, passa por um esvaziamento dos cursos de licenciatura - tanto em relação à evasão quanto em relação a um esvaziamento de sentido do que significa ser professor -, o que acontece devido aos baixos salários,à falta de plano de carreira, condições de trabalho precárias encontradas nas escolas, baixo financiamento destinado à educação básica, dentre outros, o que contribui para reforçar o desprestígio profissional da docência no Brasil (JUCÁ, 2016).

Tendo em vista que professores começam a construir sua identidade enquanto tal antes mesmo de escolherem a profissão, que a experiência enquanto estudantes na escola e na universidade influencia nessa construção,sendo produtos do meio social, político e cultural em que operam, se faz, então, necessário pensar em "transformar a prática educativa sob a perspectiva do docente, de seu universo de significados, construídos a partir de seu cotidiano" (WELP, 2016, p. 292).

Corroborando as ideias de Rajagopalan (2011) sobre Linguística Aplicada, é necessário

[...] pensar a linguagem no âmbito da vida cotidiana que nós estamos levando. Não fazendo grandes elucubrações. Daí, a diferença entre a linguística dita teórica e a linguística aplicada. É pensar, não como se pensou durante muito tempo: levar a teoria para a vida prática. Mais que isso, é usar a prática como próprio palco de criação de reflexões teóricas, ou seja, neste âmbito teoria e prática não são coisas diferentes (RAJAGOPALAN, 2011, p. 76).

Nesse sentido, Miller (2013) levanta quatro justificativas para a pesquisa em formação de professores na Linguística Aplicada. A autora aponta que 
[...] ela traz, em primeira instância, fortalecimento acadêmico para as práticas de formação de professores, já que ajuda a aprofundar o entendimento dos processos de formação, tanto inicial quanto continuada. A segunda contribuição tem se manifestado no campo metodológico, a partir do momento em que as investigações na área têm desenvolvido inovações alinhadas com a pesquisa qualitativa e interpretativa nas ciências sociais. A terceira contribuição da pesquisa é de ordem política dentro da academia, já que ela tem alavancado o status institucional dos formadores de professores, tanto no Brasil quanto no exterior. A quarta contribuição da área, e talvez a mais significativa dentro da LA contemporânea, é a que se relaciona a questões de transformação social, de ética e de identidade dos diversos agentes envolvidos em processos de formação de professores (MILLER, 2013, p. 100).

A formação de professores, dessa forma, se expande para uma posição de destaque na Linguística Aplicada, pois, como afirma Medrado (2016), não há

[...] outra maneira de transformar a relação de diferentes - professor[es] e aluno[s] - se não for pela superação de barreiras atitudinais e pela compreensão (jamais aceitação ou tolerância) da diferença que me constitui e que constitui o outro. Isso implica dizer que é na formação inicial [e continuada] que podemos ressignificar um conceito de diferença e alteridade (MEDRADO, 2016, p. 267, grifos da autora).

Colocando em evidência a formação de professores de língua estrangeira, mais precisamente o inglês (lugar que ocupo), tem sido levantada a necessidade de que haja uma mudança relevante nas políticas, nos programas, nos métodos e nos materiais relacionados ao ensino de língua inglesa e à formação de professores (KUMARAVADIVELU, 2012). Para que haja tal mudança, Kumaravadivelu afirma que "precisamos primeiramente ir além da transmissão de modelos de formação de professores"2 (KUMARAVADIVELU, 2012, p. 7).

Sendo assim, como aponta Rajagopalan (2003), é importante se levar em consideração a dimensão ética existente nas teorias linguísticas: aspecto premente desde a definição de seu objeto (a linguagem) e que passa pela concepção de sujeito adotada para se proceder nas pesquisas. "O sujeito de linguagem, como indivíduo dotado de livre-arbítrio e de uma potencialidade que lhe é geneticamente assegurada" (RAJAGOPALAN, 2003, p. 50) é comumente encontrado como subjacente às pesquisas em linguística, porém dentro de tal concepção o sujeito é um ser solitário e autossuficiente. Seguindo o pensamento do autor, a sociedade viria posteriormente e se caracterizaria por um agrupamento de seres humanos autossuficientes e isso se reflete

\footnotetext{
2 "We need to first go beyond the transmission models of teacher education".
} 
na maneira de produzir conhecimento dentro da área e, portanto, se faz necessária uma outra forma, por isso Rajagopalan defende que "o que a Linguística Aplicada precisa com urgência é repensar sua própria razão de ser enquanto disciplina [...] é preciso repensar a própria relação 'teoria/prática'.” (RAJAGOPALAN, 2003, p. 79-80, grifos do autor).

\section{UMA REFLEXÃO A RESPEITO DO PROGRAMA DE MONITORIA}

É no caminho de repensar a relação teoria/prática que este trabalho percorre, pois ele parte das reflexões resultantes das atividades de um programa de monitoria em contexto de formação inicial de professores de inglês. Assim sendo, antes de predeterminar categorias, conceitos e teorias para depois aplicá-las na prática - como é próprio da tradição positivista -, foram centralizadas as necessidades singulares de cada aluno participante do projeto de monitoria para o desenvolvimento das atividades.

O programa de monitoria foi desenvolvido no primeiro semestre do ano de 2018, como prática integrada à disciplina intitulada Inglês Básico em um curso de Letras de uma universidade pública brasileira. Com caráter extracurricular, este programa se baseia em uma atividade de ensino-aprendizagem que possibilita a ampliação da formação acadêmica e, como resultado, "denota ao cursista um salto de qualidade em sua formação porque ele conhece, de perto, o trabalho do docente universitário, principalmente numa disciplina/componente curricular que cursou anteriormente" (DANTAS, 2014, p. 573). Nesse sentido, enquanto monitor do programa me coloquei à disposição dos alunos da disciplina para dirimir possíveis dúvidas, auxiliar em atividades que seriam apresentadas à disciplina, sempre com a orientação da docente que a ministrava, pensando que "o estudante deva ser o centro da educação, do ensinoaprendizagem"3 (GONZÁLEZ et al., 2016, p. 164). Meus encontros tanto com a docente quanto com os estudantes eram individuais e semanais com a duração de uma hora em cada um deles.

Encarada nos dias de hoje como "uma modalidade de ensino e aprendizagem que contribui para a formação integrada do aluno nas atividades de ensino, pesquisa e extensão dos cursos de graduação" (VICENZI et al., 2016, p. 89), é possível localizar ocorrência de atividades de monitoria desde a Idade Média. Frison (2016) traça um

\footnotetext{
3 “el estudiante debiera ser el centro de la educación de la enseñanza-aprendizaje".
} 
histórico no qual ela aponta o desenvolvimento de atividades em que estudantes e mestres atuam conjuntamente no processo de ensino-aprendizagem desde o século XII até os dias atuais, salientando que na base da monitoria os alunos são responsáveis pelo seu processo de aprendizagem e que ela seria "uma das mais úteis invenções pedagógicas modernas" (FRISON, 2016, p. 138).

Partindo da premissa que "ensino-aprendizagem é um processo em que está sempre presente, de forma direta ou indireta, no relacionamento humano" (CANDAU, 2012, p. 14), todo o programa de monitoria foi pensado para atender as demandas singulares de cada estudante que se propôs a participar dele, fosse para aprimorar seus conhecimentos de língua inglesa, para sanar dúvidas e dificuldades ou ainda para preparar seminários que seriam apresentados na disciplina. Nesse sentido, Candau afirma que o processo de ensino-aprendizagem é multidimensional e que "para ser adequadamente compreendido, precisa ser analisado de tal modo que articule consistentemente as dimensões humana, técnica e político-social" (CANDAU, 2012, p. 14). A ênfase no relacionamento humano, na relação dos estudantes entre si e entre estudantes e a docente da disciplina fez com que se criasse um ambiente de parceria, no qual o principal alvo se tornou não apenas o desenvolvimento das questões linguísticas, senão também o reconhecimento de questões socioafetivas que atravessam o ambiente de aprendizagem, bem como a maneira única como tais pontos eram apresentados por parte dos estudantes.

A singularidade "é [a] característica do que é pouco frequente, fora do comum, extraordinário, distinto, que não tem correspondência com outro, surpreendente, incomum [...], ou seja, possui uma particularidade, uma originalidade, uma excentricidade” (BRISKIEVICS, 2018, p. 81). Nesse sentido, todos os participantes trouxeram para o programa de monitoria suas experiências, seus conhecimentos, questionamentos, saberes e inquietações, pois

[...] conhecer a cada estudante se converte em peça chave, pois será precisamente esse conhecimento o que permite não tanto 'adaptar', mas desenhar processos para atender às necessidades de cada um e especialmente servirá para começar uma relação que se converta em um encontro interpessoal (GONZÁLEZ et al., 2017, p. 170) ${ }^{4}$

\footnotetext{
4 “[...] conocer a cada estudiante se convierte en pieza clave pues será precisamente ese conocimiento el que permita no tanto «adaptar» sino diseñar procesos para atender a las necesidades de cada uno y especialmente servirá para entablar una relación, que se convierta en un encuentro interpersonal."
} 
Enfatizo esse ponto, pois essa foi uma das preocupações que se pensou como caráter desse programa de monitoria, a saber: “[...] um espaço para a visibilidade dos singulares [...], um espaço para a afirmação da identidade, para a sedimentação da certeza de que se tem um lugar no mundo, lugar onde todos devem ter voz e vez" (BRISKIEVICS, 2018, p. 91), entendendo que isso é crucial quando se trata de um ambiente de aprendizagem, principalmente em língua estrangeira. Assim, a maior parte das atividades desenvolvidas na monitoria se deram de maneira oral, através de diálogos, nos quais conversávamos em língua inglesa e juntos - eu, como monitor, e os alunos da disciplina de Inglês Básico -, geralmente através de algum material preparado para iniciar a conversa e instigar o compartilhar de sentidos, estabelecíamos um ambiente de troca de saberes. Com esse modo de proceder, o programa de monitoria se mostrou muito produtivo e resultou em muitas reflexões desde seu estágio inicial, que se deu antes dos encontros com os alunos da disciplina, reunindo-me com a docente orientadora do programa; durante o programa, com os alunos monitorados, e após o encerramento do programa, em retrospectiva.

Dentre as reflexões que foram feitas a partir dessa experiência de monitoria, gostaria de destacar, primeiramente, aquela que decorreu anteriormente aos encontros com os alunos. Mesmo já tendo ministrado aulas de idiomas em institutos de língua privados, escola pública e até em empresas, meu maior empecilho foi o de lidar com a chamada "síndrome do impostor" (BERNAT, 2008). Impostor é "caracterizado por sentimentos de inadequação, fraude ou inautenticidade pessoal, autodúvida, crença de baixa eficácia e, às vezes, ansiedade generalizada" (BERNAT, 2008, p. 01) ${ }^{5}$. Bernat (2008) argumenta que professores de Língua Inglesa sofrem de um sentimento de inautenticidade e fraude, não necessariamente relacionado a conquistas, mas relacionados ao papel de professor de uma língua estrangeira não sendo nativos em um mundo que valoriza a natividade.

Desde o momento em que entrei no programa de monitoria, o pensamento recorrente de incapacidade e inautenticidade foi uma constante. Nesse processo, os encontros com a professora orientadora do programa foram fundamentais para que eu pudesse ressignificar a forma como me percebia enquanto professor de inglês e me sentir menos inapto para desempenhar meu papel como monitor. Em tais encontros

\footnotetext{
5 "characterized by feelings of inadequacy, personal inauthenticity or fraudulence, self-doubt, low selfefficacy beliefs, and sometimes generalized anxiety"
} 
pude expor com sinceridade como eu via minhas experiências com docência anteriores invalidadas por estar em um contexto universitário, monitorando colegas de curso. Um eixo central no qual gravitava esse sentimento de incapacidade foi o fato de eu ser um aluno do referido curso de graduação em Letras monitorando meus pares.

Nesse sentido, foi de suma importância construir com os alunos monitorados uma relação de parceria e compartilhamento de experiências, muito mais no sentido de estarmos estudando juntos do que se eu estivesse numa posição hierárquica de superioridade na qual mensuramos quem sabe mais. Desse modo, foi possível contornar o desconforto e focar na troca de experiências com os alunos e a professora. Não acredito que tenha superado definitivamente essa questão da autoestima, mesmo porque é um sentimento que subjazia as atividades que preparava ou aplicava durante o programa, portanto, uma questão emocional que ultrapassa a racionalidade. Desse modo, sinto que foi um esforço hercúleo, mas necessário, no qual foi possível trabalhar com os alunos “em 'devenir' [...], [tendo] origem nas contradições que envolvem o 'ato de ensinar' e o 'ato de aprender' que se apresentam circundados pela problematicidade mais ampla da sociedade atual” (RAYS, 2012, p. 52, ênfase no original).

Nesse sentido, no qual a razão e a emoção dialogam, foi possível notar que eu não era a única parte que carregava um conflito em relação às próprias habilidades. Desde o primeiro encontro com cada estudante afirmei que não utilizaria a mesa que era destinada ao professor, pois não me sentia adequado a ocupar aquele papel e também porque queria estabelecer outro tipo de relação no ambiente de monitoria. Acredito que o maior intuito por trás desse gesto foi o de dissipar um pouco a minha própria ansiedade, porém esse ato singelo de reconhecimento aliado ao investimento dos alunos monitorados foi um marco que possibilitou trocas de forma mais horizontalizada, criando um espaço seguro no qual pudéssemos agir em língua inglesa a despeito de nossas próprias concepções sobre nós mesmos.

Essa noção de investimento é proveniente do pensamento de Norton e McKinney (2011) e pressupõe que o aprendiz de línguas possui uma identidade complexa e múltiplos desejos. Os autores afirmam que quando o aprendiz de línguas fala, ele "não está somente trocando informações como falantes da língua alvo, mas está constantemente organizando e reorganizando um sentido de quem se é e como se 
relacionar com o mundo social" (NORTON; MCKINNEY, 2011, p. 75) ${ }^{6}$. A partir daí, entende-se que investir na aprendizagem de línguas é, ao mesmo tempo, investir na própria identidade, que, por sua vez, está em constante construção e mudança através do espaço e do tempo.

Assim, dentro desse ambiente de aprendizagem por nós compartilhado pudemos nos entender como seres de linguagem, abrindo-nos e, por vezes, deixando transparecer nossas vulnerabilidades, compartilhando experiências sobre nossa luta diária contra racismo e LGBT-fobia, para citar alguns exemplos. Também passamos por momentos de trocas sobre a construção de nossa autoimagem para que pudéssemos superar desafios que a academia nos impõe, como o falar em público seja em língua materna ou em língua adicional.

Prefere-se aqui o termo língua adicional, pois, de acordo com Friedrich e Matsuda (2014 apud JORDÃO, 2014), essa noção está mais ligada aos ambientes de aquisição, de ensino-aprendizagem. Também a partir da

\begin{abstract}
perspectiva de que em muitas comunidades brasileiras o inglês ensinado na escola seria apenas mais uma das línguas que os estudantes possam conhecer, o termo ILA [Inglês como Língua Adicional] celebraria a coexistência de várias línguas em sua insistência em não destacar uma língua em detrimento de outras,desconsiderando fronteiras políticas como demarcadoras de limites linguísticos e reconhecendo que a língua "do outro", "estrangeira", também pode ser utilizada como espaço expressivo por comunidades que compartilham de uma outra língua materna que não essa "outra estrangeira" (JORDÃO, 2014, p. 31, ênfases no original).
\end{abstract}

Esses momentos de troca foram cruciais para o andamento do programa e proporcionaram um ambiente de aprendizado mútuo, como buscar informações para seminário a respeito de temas que nem eu, como monitor, nem os estudantes monitorados tínhamos muita familiaridade. Os aprendizados propiciados em cada momento em que deixávamos de lado o formato vertical e hierarquizado, sob o qual a academia é organizada, se deram não apenas no nível acadêmico, mas também em nível pessoal e de leitura de mundo.

É importante notar que superar os empecilhos que emergem da relação indissociável entre razão e emoção no processo de ensino-aprendizagem "[...] é de longo prazo e ninguém em sã consciência deve esperar quaisquer resultados concretos

\footnotetext{
6 "when language learners speak, they are not only exchanging information with target language speakers, but they are constantly organizing and reorganizing a sense of who they are and how they relate to the social world".
} 
da noite para o dia" (RAJAGOPALAN, 2005, p. 299) ${ }^{7}$. Sobre essa questão é relevante trazer à baila Maturana (2002), pois

\begin{abstract}
[q]uando mudamos de emoção, mudamos de domínio de ação. Na verdade, todos sabemos isso na práxis da vida cotidiana, mas o negamos porque insistimos que o que define nossas condutas como humanas é elas serem racionais. Ao mesmo tempo todos sabemos que, quando estamos sob determinada emoção, há coisas que podemos fazer e coisas que não podemos fazer, e que aceitamos como válidos certos argumentos que não aceitaríamos sob outra emoção (MATURANA, 2002, p. 14).
\end{abstract}

Assim sendo, só me foi possível realizar as atividades relativas ao programa de monitoria, apresentar essas reflexões em evento acadêmico e escrever este artigo com o auxílio da professora orientadora do programa de monitoria e o esforço de me olhar com um pouco mais de gentileza, permitindo-me errar para aprender e reconhecer que esse é um lugar que posso ocupar. Pois, nas palavras de Menezes de Souza,

\begin{abstract}
o processo de ler criticamente envolve aprender a escutar não apenas o texto e as palavras que o leitor estiver lendo mas também - e talvez mais crucialmente no mundo de conflitos e diferenças de hoje - aprender a escutar as próprias leituras de textos e palavras. Isso quer dizer que ao mesmo tempo em que se aprender a escutar, é preciso aprender a se ouvir escutando. Ler criticamente implica então em desempenhar pelo menos dois atos simultâneos e inseparáveis: (1) perceber não apenas como o autor produziu determinados significados que tem origem em seu contexto e seu pertencimento sócio-histórico, mas ao mesmo tempo, (2) perceber como, enquanto leitores, a nossa percepção desses significados e de seu contexto sócio-histórico está inseparável de nosso próprio contexto sócio-histórico e os significados que dele adquirimos (MENEZES DE SOUZA, 2011, p. 132, grifos no original).
\end{abstract}

Outro ponto de reflexão importante que emerge e informa esse programa está na multiplicidade das concepções de língua existentes no meio acadêmico e no desafio de como perceber, integrar e mobilizar tais conceitos no programa de monitoria. Durante o curso de graduação de Letras somos expostos a uma infinidade de concepções de língua que vão desde a concepção aristotélica que compreende que "a linguagem verbal tem a função de exteriorizar o pensamento" (MAGNANTI, 2001, s/p.) até discussões contemporâneas informadas pela inseparabilidade da linguagem em termos epistemológicos e ontológicos. A linguagem vista como tradução, ou seja, manifestação sensível e externa da representação interna, possuindo,assim, uma função expressiva é

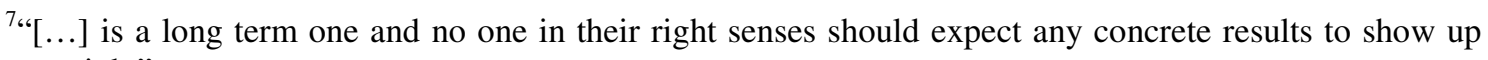
overnight".
} 
uma das primeiras - e talvez mais questionadas - concepções de língua à qual se é exposto nos cursos de graduação em Letras.

A partir daí, uma gama de conceitos de língua perpassa o aprendizado do graduando, sendo um deles a concepção saussuriana que aborda a língua como "um sistema de signos que exprimem idéias" (SAUSSURE, 2006, p. 24)e como "sistema do qual todas as partes podem e devem ser consideradas em sua solidariedade sincrônica" (SAUSSURE, 2006, p. 102). Já a concepção bakhtiniana afirma que a língua só existe localizada na comunicação entre falantes. Nas palavras do autor,

[a] língua materna, seu vocabulário e sua estrutura gramatical, não os conhecemos por meio dos dicionários ou manuais de gramática, mas sim graças aos enunciados concretos que ouvimos e que reproduzimos na comunicação discursiva efetiva com as pessoas que nos rodeiam (BAKHTIN, 2000, p. 326).

Ademais, há ainda a concepção foucaultiana que "aponta as relações entre dizer e fazer. Distanciando-se, tanto da idéia de que a palavra é a coisa quanto da concepção platônica de linguagem como representação, [...] a palavra institui a coisa, ou seja, [...] a linguagem se coloca em movimento pelos discursos" (GRANGEIRO, 2006, p. 134), entendendo a língua como tal. Foucault afirma que "a linguagem é toda ela discurso, em virtude desse singular poder de uma palavra que passa por sobre o sistema de signos em direção ao ser daquilo que é significado" (FOUCAULT, 1999, p. 132). O autor coloca a centralidade de sua concepção

não [n]os códigos, mas [n]os acontecimentos: a lei da existência dos enunciados, o que os torna possíveis - eles e algum outro em seu lugar; as condições de sua emergência singular; sua correlação com outros acontecimentos anteriores ou simultâneos, discursivos ou não (FOUCAULT, 2010, p. 09).

E ainda, há outra concepção que afirma que "linguagem é um meio social para os indivíduos em vez de um sistema autossuficiente de relações internas. Através dela não se determina o sentido ostensivamente, é um ato social dentro do qual a realidade é determinada" (ASHCROFT, 2001, p. 65) ${ }^{8}$. Ou seja, essa miríade de conceitos e discussões teóricas acerca da língua permeiam as práticas sociais do ambiente de ensino-aprendizagem e tais reflexões auxiliam e complexificam o fazer pedagógico.

\footnotetext{
8 "language is a social medium for individuals rather than a self-sufficient system of inner relationships. Though it does not determine meaning ostensively, it is a social act within which reality is determined".
} 
Durante o programa de monitoria nos alinhamos mais às concepções foucaultiana e bakhtiniana de língua.

Tendo em vista que "os paradigmas não são permanentes: historicamente, são mutáveis, relativos e naturalmente seletivos" (FREIRE; LEFFA, 2013, p. 60), cada uma dessas concepções de língua(gem) vai modular a maneira como se trabalha com o ensino de línguas e, nesse sentido, como aponta Jordão, ao adentrar nesse campo "a partir da língua inglesa, a situação se complexifica ainda mais, especialmente diante da instabilidade dos sentidos atribuídos pela comunidade científica aos termos língua franca, língua internacional, língua global, língua estrangeira" (JORDÃO, 2014, p. 14 grifos da autora). Ou seja, uma outra problemática é lidar com o mar de conceitos que são discutidos na academia e pensar em uma prática do ensino de línguas que se entrelaça reflexiva e criticamente a esses conceitos.

Rajagopalan (2003) afirma que as teorias são "tentativas de fazer sentido para um mundo real que, na ausência de tais teorias, deixar-nos-ia embasbacados diante de tantos fenômenos que escapam ao nosso senso comum" (RAJAGOPALAN, 2003, p. 18). A partir desse pensamento, foi comum levantar o questionamento de qual das teorias sobre a linguagem abordadas no curso de Letras seria a que melhor faria sentido para o programa de monitoria, qual delas seria a mais adequada e se ao se valer dos arcabouços de uma ou outra concepção de língua automaticamente as outras seriam invalidadas. Longe de almejar uma resposta definitiva, esses questionamentos foram importantes para o desenvolvimento do programa, pois essas inquietações recorrentes serviram como força motriz para a elaboração das atividades. Conceber a língua enquanto discurso e prática social (FOUCAULT, 1999; BAKHTIN, 2000) foi o ponto de partida, porém os recursos decorrentes de variadas correntes teóricas da linguagem puderam ser vivenciados devido à heterogeneidade dos alunos monitorados, a suas necessidades e à maneira como melhor pudéssemos chegar, coletivamente, a um entendimento do assunto que estivesse sendo discutido.

Entendendo que, para ser efetivo, o ambiente de ensino-aprendizagem "deve ser sensível a um grupo particular de professores ensinando um grupo particular de aprendizes, buscando um conjunto de objetivos particular dentro de um contexto institucional particular integrado em um ambiente sociocultural particular" 
(KUMARAVADIVELU, 2003, p. 34) ${ }^{9}$, foi necessário durante os encontros com os alunos da disciplina de Inglês Básico se utilizar de variadas estratégias para atingirmos os objetivos propostos pelo programa. Ao longo dos encontros de monitoria com os alunos, a prática de sala de aula mais comumente utilizada foi a de discutir a respeito de um tema, que geralmente havia sido trabalhado em aula pela docente ministrante da disciplina, utilizando um texto ${ }^{10}$ como ponto de partida. Isso ocorria com o intuito de iniciar um diálogo para propiciar as trocas de saberes e negociações de sentido, bem como trazer à tona questões que fossem interessantes para os participantes, dúvidas, questionamentos, questões relevantes à vida acadêmica no seu sentido amplo.

Assim, agindo na língua inglesa, compartilhávamos experiências e leituras de mundo de modo que nos aproximássemos mais do objetivo do programa a cada encontro. Contudo, como a proposta era centrar nos alunos monitorados e em suas necessidades, foi necessário, por vezes, adaptar a abordagem ou até mesmo os temas dos encontros, bem como utilizar textos que fossem de assuntos ou interesses mais próximos aos estudantes (como a área da saúde) ou, ainda, utilizar livros-texto para suprir necessidades de caráter mais estrutural. Eventualmente as abordagens se sobrepuseram e foi necessário trazer à lousa exemplos da produção oral dos estudantes durante a discussão de algum texto ou assunto para que houvesse o reconhecimento da sentença produzida, prática comum em abordagens tradicionais. $\mathrm{O}$ interessante de se observar aqui é que a prática de sala de aula, ou abordagem de ensino escolhida, nunca foi anterior às necessidades dos alunos. A sensibilidade do trabalho de monitoria estava em perceber o aluno e sua relação com a língua inglesa, para então adotar práticas que pudessem auxiliá-lo a aproximar-se de um aumento de sua autoestima e do uso da língua inglesa.

Assim, a partir dessas experiências do programa de monitoria, foi possível desenvolver uma sensibilidade a respeito de como as formulações teóricas sobre língua(gem) operam no momento da prática pedagógica, percebendo que o tornar-se professor não acontece num contínuo linear desde aprender conceitos para serem aplicados posteriormente. No entanto, acredito que o maior aprendizado que construí,

\footnotetext{
9 "must be sensitive to a particular group of teachers teaching a particular group of learners pursuing a particular set of goals within a particular institutional context embedded in a particular sociocultural milieu".

${ }^{10}$ Texto aqui é entendido como um termo amplo, não designando apenas o texto escrito, mas podendo ser imagens, vídeos etc.
} 
nesse sentido, foi o de que a prática pedagógica é muito dinâmica e que as formulações teóricas existentes não determinam a prática real - o momento real entre professor e aluno - num sentido estrito, mas uma influencia e informa a outra. Houve, também, um trânsito que precisou ser feito entre uma e outra concepção para que se pudesse atingir o objetivo proposto para melhor atender às demandas dos estudantes. Em suma, nenhuma concepção de ensino-aprendizagem encerra em si mesma a discussão sobre língua(gem) e como deve ser o proceder didático, e isso faz com que seja possível, e até mesmo necessário, trabalhar de maneira fluida com esses construtos teóricos, entendendo que tais sentidos teóricos são frutos de práticas e que tais práticas reinterpretam teorias.

Mas qual o sentido de se preocupar reiteradamente com essas questões? Qual a função ou real necessidade de transitar por esses variados construtos no ensinoaprendizagem? Ora, não é novidade entre aqueles que estão em um ambiente de ensinoaprendizagem de que ele não é homogêneo e que os sujeitos ali presentes são atravessados de inúmeras questões que transcendem o espaço institucional em que essa experiência se dá. Portanto, é ilusório querer formular a priori uma técnica de disseminação de saberes universalista, como se os alunos ali presentes fossem apenas um receptáculo, abertos ao saber de um alguém que se julga detentor do conhecimento. Pelo contrário, esse é um ambiente heterogêneo,onde sujeitos formam e transformam suas identidades continuamente de acordo com as formas pelas quais são interpelados nos sistemas culturais que os rodeiam (HALL, 2005).

Tendo isso em mente, salientar que os estudantes monitorados eram provenientes de diversos contextos se torna uma redundância e foi justamente atentar para essa realidade que complexificou a experiência do programa. Havia ali estudantes com experiências de vida prévias advindas de outras áreas do conhecimento que não Letras, assim como diferentes níveis de proficiência - aqueles que necessitavam de auxílio desde as primeiras etapas de letramento em língua inglesa e aqueles que estavam ali para "refinar" as arestas de sua produção oral e escrita, bem como aqueles que possuíam certo repertório linguístico, mas careciam da autoconfiança necessária para se sentirem confortáveis para produzir as atividades necessárias para a disciplina. Desse modo, as atividades do programa de monitoria não foram baseadas em uma abordagem meramente conteudista e homogênea, foi necessário estabelecer uma via de mão dupla para que pudéssemos construir em conjunto saberes que atingissem o objetivo da monitoria, auxiliando-os no desempenho da disciplina de Inglês Básico e, ao mesmo 
tempo, compartilhar experiências enriquecedoras de modo que nossos encontros não tivessem um caráter apenas funcional, mas de relação interpessoal.

Cabe explanar que embora a disciplina seja intitulada Inglês Básico, o nível ${ }^{11}$ que se espera atingir ao fim dela é comumente categorizado como "pré-intermediário", ou seja, o programa de monitoria veio para ajudar a sanar uma fissura que existe nas etapas iniciais do curso de Letras. Tal fissura é resultado das desigualdades existentes dentro do próprio curso de Letras e mais visível neste momento da graduação por ser uma disciplina voltada aos ingressantes do curso, e neste caso do curso noturno. Assim, espera-se que os estudantes desta disciplina sejam capazes de acompanhar aulas ministradas completamente em língua estrangeira, produzir textos e apresentações orais como parte de seu processo avaliativo, ao mesmo tempo em que a própria disciplina funciona como espaço de recepção e adaptação de calouros no Curso de Letras Inglês. Desse modo, esse programa extracurricular serviu de apoio, proporcionando um espaço para que os estudantes pudessem apresentar suas demandas para atingirem tais objetivos.

De modo geral no meio acadêmico, "o aluno universitário deve utilizar-se do discurso acadêmico e dos gêneros aceitos para uso dentro deste discurso" (FIGUEIREDO; BONINI, 2006, p. 417), nesse sentido a disciplina, que é ofertada para os ingressantes do curso de Letras, pode ser tida como um primeiro contato com tal discursividade. Durante o programa de monitoria muitos dos encontros com os estudantes monitorados serviram de espaço de discussão a respeito de trabalhos que foram solicitados na disciplina, dentre os quais havia a apresentação de um seminário. Durante esses encontros houve compartilhamentos no sentido de escolha de tema para seminário, visto que era livre, formato de apresentação, como buscar informações confiáveis, levantar dados, entre outros, enfim, como aprender a aprender. De fato, esses momentos foram muito produtivos, pois suscitaram ricas discussões sobre a "produção textual como atividade socialmente situada, realizada dentro de comunidades que possuem convenções específicas sobre a forma e o conteúdo dos textos" (FIGUEIREDO; BONINI, 2006, p. 419) e a elaboração de trabalhos nesse gênero acadêmico. Cabe ainda ressaltar que, devido ao caráter de relação interpessoal que tinham os encontros, foi preciso que a "importância de variáveis relacionadas ao papel

\footnotetext{
${ }^{11}$ É importante pontuar que entendo língua enquanto prática social, porém o currículo da disciplina se pauta em uma abordagem que define a centralidade em níveis de língua a serem atingidos pelos estudantes.
} 
de motivação, personalidade e fatores psicossociais na performance dos estudantes" (GUÀRDIA et al., 2006, p. 663) ${ }^{12}$ ocupasse um papel central e, por isso, também houve ensaios de tais apresentações como instrumento para dirimir ansiedade, nervosismo e as questões afetivas que atravessam esse tipo de performance, vivenciando com os alunos a intersecção entre razão e emoção.

\section{CONSIDERAÇÕES FINAIS}

Acredito que essas experiências vividas dentro do programa de monitoria foram muito valorosas e produtivas para a minha formação - não apenas profissional, mas como sujeito -, pois estando em um curso de licenciatura é enriquecedor poder participar de programas extracurriculares nos quais é possível ter contato com um ambiente de ensino-aprendizagem. Nesse sentido, essa experiência foi fundamental para apreender que o conteúdo linguístico não está desvinculado da "vida em sociedade, contexto sociocultural e histórico" (CAVALCANTI, 2013, p. 224), sendo necessário ter esses elementos em perspectiva para estabelecer uma relação mais horizontalizada entre os sujeitos no processo de ensino-aprendizagem.

Entretanto, Vizzotto e Chaves (2016) apontam que a formação de professores nos cursos de licenciatura é insuficiente, pois é necessário que "o futuro professor compreenda a importância da dimensão política e ética do seu agir pedagógico" (VIZZOTTO; CHAVES, 2016, p. 121). Incisiva também é a crítica feita por Saviani (2009) que afirma que a "precariedade das políticas formativas, cujas sucessivas mudanças não lograram estabelecer um padrão minimamente consistente de preparação docente para fazer face aos problemas enfrentados pela educação escolar em nosso país" (SAVIANI, 2009, p. 148). Puiati (2014), por sua vez, afirma que

[...] as exigências para a formação profissional para a docência discutidas na literatura referem-se a saberes e/ou conhecimentos necessários à docência, não somente para a sua prática, mas também para seu planejamento, para o entendimento da estrutura do ensino e para a compreensão de como o aluno aprende. E, além dos saberes/conhecimentos específicos do professor, há aqueles que dizem respeito às profissões de interações humanas, como por exemplo, questões de ética, de afetividade, de respeito, de comunicação (PUIATI, 2014, p. 41).

\footnotetext{
12 "importance of variables related to the role of motivation, personality and psychosocial factors in the performance of students"
} 
Assim, corroborando as ideias de Miller (2013) em relação

às oportunidades de formação que emergem das experiências cotidianas vivenciadas nas escolas e nas salas de aula universitárias, ainda [é] necessário buscar entender melhor, em diversos contextos, as inúmeras questões [que possam ser] levantadas (MILLER, 2013, p. 117).

No entanto, creio que as atividades extracurriculares, como o programa de monitoria, podem contribuir grandemente para a formação profissional dos licenciandos.

É importante lembrar que durante a prática pedagógica nos ambientes de ensinoaprendizagem há uma troca de saberes que favorece a aprendizagem do sujeito que ocupa a posição de docente, assim, nas palavras de Borko: “a aprendizagem ocorre em muitos aspectos diferentes da prática, incluindo salas de aula [dos professores], suas comunidades escolares e cursos de desenvolvimento profissional ou workshops" (BORKO, 2004, p.4) $)^{13}$. Este é um ponto central no programa de monitora: o de propiciar a aprendizagem de todos os envolvidos estando inserido no ambiente pedagógico. Tendo em vista que "encontra-se nos currículos dos cursos de licenciatura uma base estritamente teórica, academicista e distante da realidade da escola básica" (DANTAS, 2014, p. 586), acredito que práticas extracurriculares em docência deveriam ser amplamente difundidas nos cursos de licenciatura, pois "a monitoria no ensino superior tem se caracterizado como incentivadora, especialmente, à formação de professores" (DANTAS, 2014, p. 569) e poderá assim contribuir para a redução do esvaziamento dos cursos de licenciatura, bem como à reconstrução da identidade e dos sentidos do ser professor.

\section{REFERÊNCIAS}

ASHCROFT, B. Post-Colonial transformation. London: Routledge, 2001.

BAKHTIN, M. Os gêneros do discurso. In: BAKHTIN, M. Estética da criação verbal. São Paulo: Martins Fontes, 2000.

BERNAT, E. Towards a pedagogy of empowerment: the case of 'impostor syndrome' among pre-service non-native speaker teachers in TESOL. ELTED Journal, Coventry, v. 11, p. $1-8,2008$.

\footnotetext{
13 "learning occurs in many different aspects of practice, including their [teacher's] classrooms, their school communities, and professional development courses or workshops".
} 
BORKO, H. Professional development and teacher learning: mapping the terrain. Educational Researcher, Tallahassee, v. 33, n. 8, p. 3-15, 2004.

BRISKIEVICS, D. A. A ontologia da singularidade e a educação em Hannah Arendt: uma preparação para o mundo. Revista Portuguesa de Educação, Braga, v. 31, n. 1, p. 73-93, 2018.

CANDAU, V. M. A Didática e a Formação de Educadores - Da Exaustão à Negação: a busca da relevância. In: CANDAU, V. M. (Org.). A Didática em Questão. 33. ed. Petrópolis: Vozes, 2012.

CAVALCANTI, M. C. Educação linguística na formação de professores de línguas: intercompreensão e práticas translíngues. In: MOITA LOPES, L. P. (Org.). Linguística Aplicada na Modernidade Recente: festschrift para Antonieta Celani. São Paulo: Parábola Editorial, p. 211-226, 2013.

DANTAS, O. M. Monitoria: fonte de saberes à docência superior. Revista Brasileira de Estudos Pedagógicos, Brasília, v. 95, n. 241, p. 567-589, 2014.

FIGUEIREDO, D. C.; BONINI, A. Práticas discursivas e ensino do texto acadêmico: concepções de alunos de mestrado sobre a escrita. Linguagem em (Dis)curso, Tubarão, v. 6, n. 3, p. 413-446, 2006.

FREIRE, M. M.; LEFFA, V. J. A Auto-heteroecoformação tecnológica. In: MOITA LOPES, L. P. (Org.). Linguística Aplicada na Modernidade Recente: festschrift para Antonieta Celani. São Paulo: Parábola Editorial, p. 59-78, 2013.

FOUCAULT, M. As palavras e as coisas. 8. ed. São Paulo: Martins Fontes, 1999.

FOUCAULT, M. Ditos e Escritos VI. Rio de Janeiro, Forense Universitária, 2010.

FRISON, L. M. B. Monitoria: uma modalidade de ensino que potencializa a aprendizagem colaborativa e autorregulada. Pró-Posições, Campinas, v. 27, n. 1, p. 133-153, 2016.

GRANGEIRO, C. R. P. Michel Pêcheux e Michel Foucault: diálogos transversos sobre formação discursiva. Letras \& Letras, Uberlândia, v. 22, n. 2, p. 133-141, 2006.

GONZÁLEZ, P. P.; CORIA, G. M.; HERNÁNDEZ, J. F. C. La singularidad según la educación personalizada en la era digital. Educación, Lima, v. 26, n. 20, p. 162-181, 2017.

GUÀRDIA, J.et al. Factors Related to the Academic Performance of Students in the Statistics Course in Psychology. Quality \& Quantity, v. 40, n. 4, p. 661-674, 2006.

HALL, S. A Identidade Cultural na Pós-Modernidade. 11 ed. Rio de Janeiro: DP\&A, 2005. 
JORDÃO, C. M.; FOGAÇA, F. C. Carvalhos, juncos, árvores e rizomas: paradigmas na formação de professores. Revista Brasileira de Linguística Aplicada, Belo Horizonte, v. 12, n. 3, p. 493-510, 2012.

JORDÃO, C. M. ILA - ILF - ILE - ILG: quem dá conta? Revista Brasileira de Linguística Aplicada, Belo Horizonte, v. 14, n. 1, p. 13-40, 2014.

JUCÁ, L. Responsabilidades sociais da Linguística Aplicada na formação de professores de Língua Inglesa no contexto brasileiro: traçando novos rumos. In: JORDÃO, C. M. (Org.). A Linguística Aplicada no Brasil: rumos e passagens. Campinas: Pontes Editores, p. 233-262, 2016.

KUMARAVADIVELU, B. Beyond Methods: macro strategies for language learning. New Haven: Yale University, 2003.

KUMARAVADIVELU, B. Language Teacher Education for a Global Society: a modular model for knowing, analyzing, recognizing, doing and seeing. New York: Routledge, 2012.

MAGNANTI, C. O que se faz com a Linguagem Verbal? Linguagem em (Dis)curso, Tubarão, v. 1, n. 1, s. p., 2001.

MATURANA, H. Emoções e linguagem na educação e na política. Belo Horizonte: Ed. UFMG, 2002.

MEDRADO, B. P. Formando Professores para Incluir: contribuições da Linguística Aplicada. In: JORDÃO, C. M. (Org.). A Linguística Aplicada no Brasil: rumos e passagens. Campinas: Pontes Editores, 2016. p. 263-283.

MENEZES DE SOUZA, L. M. Para uma redefinição de Letramento Crítico: conflito e produção de significação. In: MACIEL, R. F.; ARAUJO, V. A. (Orgs.). Formação de Professores de Línguas: ampliando perspectivas. cap. 6, p. 128-140. Jundiaí: Paco, 2011.

MILLER, I. K. Formação de Professores de Línguas: da eficiência à reflexão crítica e ética. In: MOITA LOPES, L. P. (Org.). Linguística Aplicada na Modernidade Recente: festschrift para Antonieta Celani. São Paulo: Parábola Editorial, 2013. p. 99-122.

NORTON, B.; MCKINNEY, C. An Identity Approach to Second Language Acquisition. In: ATKINSON, D. (Ed.). Alternative Approaches to Second Language Acquisition. cap. 3. London \& New York: Routledge, 2011. p. 73-94.

PUIATI, L. L. Iniciação à Docência na Formação Inicial de Professores: possíveis relações entre cursos de licenciatura e subprojetos PIBID/CAPES na UFSM. 2014. 283 p. Dissertação (Mestrado em Educação) - Centro de Educação, Universidade Federal de Santa Maria, Santa Maria, 2014.

RAJAGOPALAN, K. Por uma Linguística Crítica: linguagem, identidade e a questão ética. São Paulo: Parábola Editorial, 2003. 
RAJAGOPALAN, K. Non-native Speaker Teachers of English and their Anxieties: ingredients for an experiment in action research. In: LLURDA, E. (Ed.). Non-Native Language Teachers: perceptions, challenges and contributions to the profession. cap. 15, p. 283-303. New York: Springer, 2005.

RAJAGOPALAN, K. Entrevista com Kanavillil Rajagopalan: ponderações sobre Linguística Aplicada, política linguística e ensino-aprendizagem. Revista de Letras Norte@mentos - Revista de Estudos Linguísticos e Literários, 8 ed., Estudos Linguísticos, p. 75-81, 2011.

RAYS, O. A. Pressupostos teóricos para o ensino da didática. In: CANDAU, V. M. (Org.). A Didática em Questão. 33 ed. p. 43-52, Petrópolis: Vozes, 2012.

SAVIANI, D. Formação de Professores: aspectos históricos e teóricos do problema no contexto brasileiro. Revista Brasileira de Educação, Rio de Janeiro, v. 14, n. 40, p. 143$155,2009$.

SAUSSURE, F. Curso de linguística geral. 27. ed. São Paulo: Cultrix, 2006.

SILVA, L.; SILVA, M.; ROCHA, N. V. "Let's not Forget We Are Language Teachers!": investigating critical thinking and critical reflection in the practicum of an English Undergraduate Program. Fórum Linguístico, Florianópolis, v. 14, n. 1, p. 18661879, jan-mar 2017.

VICENZI, C. B. et al. A Monitoria e seu Papel no Desenvolvimento da Formação Acadêmica. Revista Ciência em Extensão, São Paulo, v. 12, n. 3, p. 88-94, 2016.

VIZZOTTO, R.; CHAVES, T. V. Formação Inicial de Professores: reflexões e perspectivas acerca do estágio extracurricular, uma alternativa. Missões: Revista de Ciências Humanas e Sociais, São Borja, v. 2, n. 1, p. 120-136, 2016.

WELP, A. O Professor em Formação no Programa Inglês sem Fronteiras UFRGS. In: JORDÃO, C. M. (Org.). A Linguística Aplicada no Brasil: rumos e passagens. Campinas: Pontes Editores, 2016. p. 285-308. 